\section{Responsibility Unclear}

Jaap Willems from the University of Nijmegen recently surveyed senior physicists and science journalists in The Netherlands in order to identify the barriers to communicating physics to the media and ways they may be overcome. The results were reported in the bulletin of The Netherlands Physical Society [Nederlands tijdschrift voor Natuurkunde 62 (1996) 59]. They indicated that most Dutch physicists felt popularization was needed, but had different opinions on who was responsible, especially since science journalists, while interested in physics, were handicapped by a low estimation of their own knowledge which led to a reliance on popular science magazines.

Recent research shows that Holland's mass media give little attention to science in general and to physics in particular [1]. This is fundamentally not a problem unless the public and physicists feel that the situation is undesirable. However, both criticize the media. The public wants to know more about physics because of the money spent on research. It also worries about the future owing to what is happening in science. Meanwhile, physicists seek public support more and more due to their funding needs.

US surveys have shown that $40 \%$ of the population is interested in science [ 2 , 3], and that many people want to learn about science from newspapers and television. The level of interest in Holland is unknown, but the popularity of science lectures, specialised science magazines, books about physics and so on gives the impression that physics is very popular.

Nevertheless, improvements are possible and barriers to popularising science

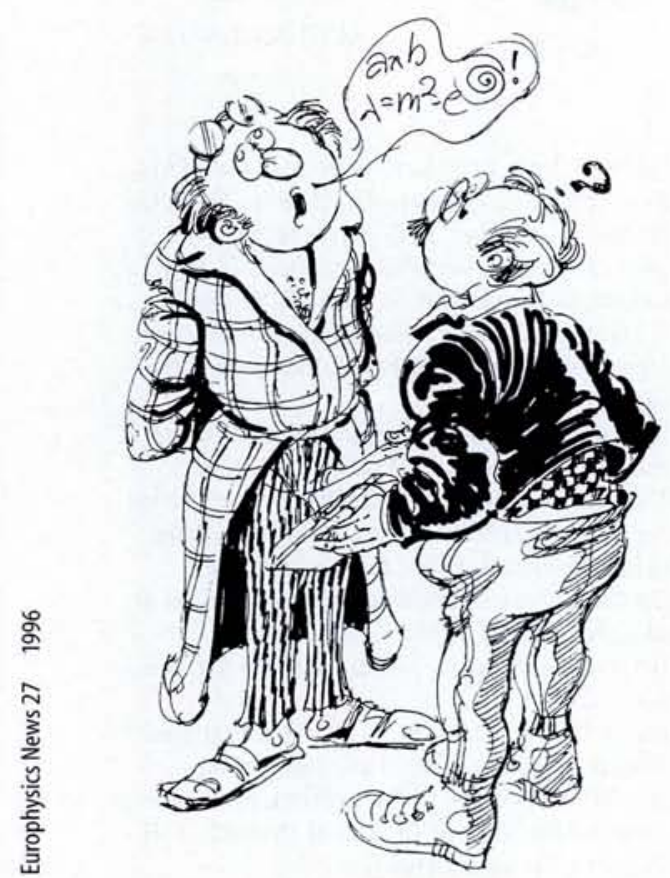

do exist. A survey carried out in 1995 in Holland of 30 well-known physicists from universities and research laboratories and 20 science journalists working for newspapers aimed to identify the barriers to popularizing physics through communication between physicists and journalists [4].

\section{TV Better}

All of the physicists said that popularizing physics is necessary, with only three expressing some reservations. As one explained: "Physics is everywhere in society but most people do not know how important physics is for everything. More and more people do not want to know about physics. That is dangerous. Even politicians do not know since most have an education in the arts".

Most also said that television offered the best medium for popularizing physics, but they were unhappy with the way television journalists treated the different fields of physics. The daily newspaper was the next best medium, and newspaper journalists were the more highly regarded.

All of the journalists said that they were interested in physics, but many had problems with its specialised and abstract character. One stated: "Physics is often too specialised, and physicists are most of the time unable to explain things: they know much about a very small field."

\section{Interested Generalists}

Most of the journalists had to cover a variety of specialties in science. Part (1a) of the table shows that all were interested in physics to a moderate-to-large extent: those with a broad, general interest in science had a major interest, and even those reporting on a broad range of topics (not only science, but also medicine and the arts) were moderately interested.

Most of the journalists were educated as scientists, seven as physicists, so it seemed obvious that they were more-orless experts in science. However, US sur-
Results of a 1995 Dutch Survey of 30 physicists and 20 science journalists

1. Science journalists (no. of replies)

(a) Interest in various scientific disciplines

$\begin{array}{llll} & \text { major } & \text { moderate } & \text { none } \\ \text { Biology } & 13 & 4 & 2 \\ \text { Physics } & 13 & 7 & 0 \\ \text { Chemistry } & 5 & 11 & 4 \\ \text { Technology } & 10 & 6 & 4 \\ \text { Informatics } & 5 & 7 & 8 \\ \text { Medicine } & 5 & 8 & 7 \\ \text { Astronomy } & 13 & 3 & 4 \\ \text { Earth sciences } & 14 & 3 & 3\end{array}$

(b) Self-estimated knowledge of physics

$\begin{array}{ll}\text { very good } & 2 \\ \text { good } & 9 \\ \text { moderate } & 6 \\ \text { bad } & 1 \\ \text { no answer } & 2\end{array}$

(c) Use and appreciation of some science magazines

$\begin{array}{lll} & \text { use } & \text { highly appreciate } \\ \text { New Scientist } & 20 & 11 \\ \text { Science } & 15 & 7 \\ \text { Nature } & 15 & 6 \\ \text { Scientific American } & 13 & 3 \\ \text { CERN Courier } & 13 & - \\ \text { Science News } & 5 & 1 \\ \text { Physics Today } & 4 & -\end{array}$

2. Physicists (no. of replies)

(a) Who should take the initiative in contacting journalists?* Investigator 6 Head of Department 5 Board of Directors 6 Information officers $\quad 16$ Others

(b) Who should select the information ?*

$\begin{array}{ll}\text { Investigator } & 11 \\ \text { Head of Department } & 9 \\ \text { Board of Directors } & 7 \\ \text { Information Officer } & 10\end{array}$

(c) Ways to improve contacts with the media*

Courses for physicists in science writing

Courses for physicists in communication with journalists 13 Courses for journalists in communication with scientists 6 Courses for journalists in science

* Some physicists gave more than one reply.

veys show that journalists often do not completely understand their material [2]. Many of the journalists said that they were essentially generalists: only two said their knowledge of physics was very good, $(\mathrm{lb}$ in table) and a few with university degrees in physics estimated their expertise as moderate, which is strange.

The journalists kept abreast by reading science magazines like Science and Nature - part (1c) of the table - and by attending scientific meetings $[2,5]$. They generally did not appreciate conferences (too expensive; take too much time). The only highly valued meeting was the annual meeting of the American Association for the Advancement of Science. The journalists who did not possess a degree appreciated magazines like Scientific American. 


\section{Informal Rules}

Formal rules covering the communication of research results can raise barriers between scientists and science journalists since they hamper and frustrate contacts [2]. Among the public-sector physicists, only one mentioned the existence of rules (erroneously in fact). Those working in the state-supported research and development agency TNO mentioned similar rules (all contacts with journalists should be arranged by a special department after permission has been granted by a department head). But they said that formal rules had never raised barriers to communicating with journalists. Similarly, physicists from industrial research labs mentioned that they were also subject to rules on communicating results, but that they too did not raise barriers.

Parts (2a) and (2b) of the table show that most respondents felt that the individual physicists themselves should normally neither make contact with the media nor decide on the information to transmit (the total number of answers was larger than the number of respondents because some gave more than one answer). About onehalf mentioned informal rules concerning media contacts, but only two said they could raise barriers with journalists.

\section{Courses Needed}

Most respondents had considerable experience of contacts between physicists and science journalists, and there were few complaints about the quality of the contacts. Part (2c) of the table shows that many of the physicists felt that courses in science writing offered the best way to improve communication with the press.

Barriers between physicists and science journalists also arise when scientists are incapable of explaining their work. When a physicist writes for the general public about a research topic one assumes that he or she would also be able to explain the topic to journalists. About one-half of the physicists had written for popular science magazines, although the reaction of colleagues was not always positive since some did not appreciate the popularization of science by fellow scientists.

Nearly all those who had popularized physics admitted that writing in a popular style was difficult - more difficult than writing a scientific publication. None of the respondents had followed a course on the popularization of science. Some physicists regretted the lack of such a training; others thought that they did not need it.

The science journalists expressed differences of opinion about the capability of scientists to explain their work; some stated that scientists were incapable of doing so, others had a good experience. The firm opinions expressed by some physicists are worth noting:

"Physicists make their work more diffcult than necessary. Chemists are more capable of explaining their work; they have learnt to communicate. Biologists are the best in science communication. Perhaps this is because of the character of biology. Physicists still have to learn how to communicate with the public."

"Most physicists are able to explain their work if you as a journalist ask the right questions. But most physicists indeed have difficulty in imagining the world of the layman: it is difficult for them to place themselves in a layman's way of thinking".

\section{References}

[1] J. Willems, Wetenschao op de Nederlandse tv, Massacommunicatie 19 (1991) 3.

[2] Ch. Petit, Getting physics into the paper, Physics Today (Nov. 1990) 35 .

[3] G. Tressel, Science in the air, Physics Today (Nov. 1990) 24.

[4] J. Willems, Fysici en journalisten over populariseren van natuurkunde, Nederlands tijdschrift voor Natuukunde 62 (1996)59.

[5] D. Nelkin, Selling science, Physics Today (Nov. 1990) 41.

\title{
CALL FOR PROPOSALS
}

Installation profile:

LURE: Synchrotron Radiation Laboratory - FRANCE

LURE is one of the biggest European facilities dedicated to the use of Synchrotron Radiation (SR). It has two storage rings using positrons. A linear accelerator feeds both the DCI and SUPER ACO storage rings. The former produces $\mathrm{X}$ rays in the energy range of 2 to $50 \mathrm{KeV}$, with hard $\mathrm{X}$ rays provided by a superconducting wiggler. The latter produces radiation in the range from far infrared to soft X rays $(5 \mathrm{KeV})$. Some 40 experimental stations, 20 on each ring, can be operated simultaneously. Most SR applications are possible, but there is special emphasis on molecular and atomic physics, surface sciences, absorption spectroscopy, diffraction and biology.

A special feature of LURE is the important use of the time structure (SUPER ACO operates $50 \%$ of the beam time in the 2 bunches mode).

The storage rings operate 4 days per week on SUPER ACO and 5 days per week on DCI, totalling 171 runs on SUPER ACO and 175 runs on DCI per year.

Project overview:

So far, and thanks to successive programms from the Commission of the European Communitics (CED) for the access to large seale facilities (LIP, IICM, TMR), scientists from the European Union (EU) Member States have completed more than 400 experiments at LURE. Usage by project participants totalled $25 \%$ of the total time available at the facility.

Call for Proposals:

Scientific experiment proposals are selected once per year by peer review panels (named programm committees by LURE) on the basis of scientific excellence.

For the experiments to be performed in 1997, proposals must be submitted by:

\section{0th November 1996}

on forms which can be obtained (as well as general informations) from:

\author{
LURE Scientific Secretary \\ To Michèle LE MOZE \\ Bâtiment 209D \\ 91405 ORSAY Cedex \\ Phone number: 33164468014 \\ Fax number: 33164464148 \\ Mail address: lemonze@lure.u.psud.fr
}

Expenses:

When a project has been accepted, the LURE, under the CEC-TMR programm for the Access to Large Scale Facilities, can reimburse travel and per diem expenses under the following conditions: a researcher given access to the Facility is eligible to receive reimbursement of travel and expenses only if he is both a national of a Member State of the Community or Associated State and is conducting research inside the Member States of the Community or Associated States, but outside the country in which the Facility is located (in the present case outside FRANCE). 